$\begin{array}{ll}\text { Variants } & \begin{array}{l}\text { Variants } \\ \text { The Journal of the European Society for Textual } \\ \text { Scholarship }\end{array}\end{array}$

15-16 | 2021

Textual Scholarship in the Twenty-First Century

\title{
Paul Eggert, The Work and the Reader in Literary Studies: Scholarly Editing and Book History
}

\section{Hans Walter Gabler}

\section{OpenEdition \\ Journals}

Electronic version

URL: https://journals.openedition.org/variants/1505

DOI: 10.4000/variants. 1505

ISSN: 1879-6095

\section{Publisher}

European Society for Textual Scholarship

\section{Printed version}

Date of publication: 1 July 2021

Number of pages: 273-277

ISSN: 1573-3084

\section{Electronic reference}

Hans Walter Gabler, "Paul Eggert, The Work and the Reader in Literary Studies: Scholarly Editing and Book History", Variants [Online], 15-16 | 2021, Online since 01 July 2021, connection on 16 July 2021. URL: http://journals.openedition.org/variants/1505 ; DOI: https://doi.org/10.4000/variants.1505 
Review of Paul Eggert, The Work and the Reader in Literary Studies: Scholarly Editing and Book History. Cambridge: Cambridge University Press, 2019. 242 pp. ISBN: 978-1-10-864101-2.

Which academy, one wonders, would venture a summer school or sabbaticalterm training camp for experienced textual scholars together with early-career hands-on (analogue) and "keys-on" (digital) editors for the purpose of exchanging practical experience from their variegated individual tasks and projects in the scholarly editing and digital exploration of texts and works of literature? The circle of participants should be international, representing distinctly different schools of expertise. It should also, for an essential backgrounding of theoretical conceptions and methodological reflections, comprise the literary and literarygenetic critic, as well as the interdisciplinary digital humanist. An assembly on such scale would convene the competence for searching dynamic investigations of the literary foundations of our cultural heritage and their future, as well as past, medial unlocking. It would be well served with Paul Eggert's monograph of 2019 from Cambridge University Press, The Work and the Reader in Literary Studies to kick it off, and from there to develop exchanges to exemplify and counter-exemplify, substantiate, modify, or critique the tenets, positions, and systematizations the book offers.

The Introduction towards laying out in manifold detail that " $[\mathrm{t}]$ he present book [... centres itself around the much overlooked concept of the work" (9) is first a warmingly personal, then a stimulatingly sweeping appetizer to the book's perspectives and argument. Before anatomising the centre, the second chapter, in a rhetorical sweep typical of Paul Eggert, "revives the work concept" triadically via music, literature, and historic buildings. The work concept is so at once holistically modelled on the art form of music in a "continuity from composer to score to performers to audience" (22). The third chapter draws us fully into the book's core area of expertise, that of textual criticism and scholarly editing. As guided, though, by a seasoned practitioner and theorist of AngloAmerican textual criticism, we are taken on a route of proper schooling in the template of that discipline, Shakespeare editing in printed scholarly editions. Once more, the rhetorical strategy is thus delightfully oblique ("By indirections 
find directions out", as Polonius in Hamlet, II.i.65, phrased it). Eggert's opening gambit for this chapter is to imagine a digital native's first encounter with that dinosaur from analogue times, the editing of Shakespeare, touchstone for principles and practice of editing in the Anglo-American environment. In a crash-course manner, the chapter climbs rapidly to the book's full professional heights. It culminates in analytics suited to enlighten, even redirect Shakespeare editing itself — and so unashamedly leaves the digital neophyte well behind.

In its two subsequent chapters, under the headings "The Reader-Oriented Scholarly Edition" (4) and "Digital Editions: The Archival Impulse and the Editorial Impulse" (5), the book reaches its core systematics. Significantly, the "reader-orientation", essential as it is for Eggert's overall triadic conception encapsuled in the book's title, is established and argued first in Chapter 4. This sets out from the definition that editions are arguments, and that they are transactional (64). While Eggert concedes that "editions may have succeeded brilliantly in their presentational role", he also emphasises that "they have failed, or at least partially failed, in their transactional one" (67). The vision therefore "is a more reader-oriented scholarly edition than has been feasible in print" (76). The sights are thus directed on support from the digital medium. Chapter 5, "Digital Editions", builds up to devise design and format for digital editing and digital editions of the present and for the future. To order theoretically and pragmatically what in documents and transmissions editors encounter and what, in combination, their preservational, presentational and transactional responsibilities should comprise, Eggert models the editorial and interpretatively critical, and thus always readerly, trajectory of engagement with text, work, and reading onto a sliding scale between an archival and an editorial impulse. The slider is, at one level, theory visualised. It brings into an, as it were, living image a coherent conception of the centrality that textual criticism and scholarly editing occupy, or should occupy, for literary studies. At another level, essential for the book's developing argument, it positively models our present and future commitment to scholarly editing into the digital medium. Eggert recognises "an expanded remit for scholarly editors in the digital medium, one that might begin to resolve, through practice, the old stand-off between literary scholarship and literary criticism" (80). The model and device of the slider becomes the template for situating the book's work concept in literary studies, pivoted on the editor:

If the edition is to be seen as an argument then it is necessarily one that is addressed to an audience in respect of the documents gathered and analysed for the editorial project, usually documents deemed to witness the textual transmission. If the edition is an argument addressed to a readership then it must anticipate the needs of that readership. This transactional view of things places the editor in a medial or Janus-faced position, looking in one direction towards the relevant documents and looking in the other towards the audience. 
The four chapters to follow are pragmatic in their main orientation. They live from Paul Eggert's stunningly rich and variegated practical experience of editing and from his capacity to differentiate, generalise and theorise from it. From his intense work of conceptual and editorial cooperation on the Australian Charles Harpur Critical Archive (2019), he refines, in Chapter 6, the book's "work concept" through introducing its sub-granularity "version". The version is fore-grounded as a significant element in an edition's work-directed argument. Chapters 7 and 8 address "Book History and Literary Study" in an increasingly urgent plea for the transactional dimension of the "work edition" of the future. At the present moment in the field of literary studies, as well as in its foundational sub-disciplines of textual criticism and editorial scholarship, it is indeed urgent to establish, or re-establish, book history as a main tributary to knowledge and historical insight. Book history today is no longer the positivistic discipline that it once was. Drawing it in as a main factor in his pragmatic concerns, Eggert decisively strengthens its relevance to literary studies, and consequently to scholarly editing, in comprehensive commitment to the reader. Chapter 7 on such terms works out the commercial and ultimately cultural relevance both "at home in the colony" and "far away in England" of the Australian writer Rolf Boldrewood. Chapter 8 addresses the literary creativity of Joseph Conrad and D.H. Lawrence, once more in terms of book history. We partake again of Paul Eggert's first-hand editorial experience from co-operating in these editions, conceptually refined now in terms of his monograph's lode-stars of a versionrefined work concept and the transactional commitment postulated for the editorial enterprise. To cap this pursuit, Chapter 9 engages with adaptations. The description of the manifold variations of the "Ned Kelly Story" under a Robin Hood template easily persuades that this chapter belongs and is indeed a logical follow-up of the book's over-all argument. Adaptation, accordingly, is a mode of reception engendering new production, "but the new production will be subject to the different cultural valencies of its time and place, when and where it must establish its own readership or audience or participatory user base" (157). The literary historian will easily appreciate that this is a constant in cultural history and applies for instance to medieval epics, Shakespearean plays, or Dickensian novels alike.

The Conclusion stringently draws together the perspectives, lines of argument and postulates the book has developed. What I was yet unaware of when I volunteered to review it for Variants was that a series of articles I had written since 2006 would serve Paul Eggert's monograph as springboard for giving the book's tenets their final edge and profile. I greatly appreciate that I should have in effect moulded an echo chamber for them. The overtones of resonance between us in that chamber will and should be heard by the community of fellow researchers at large - and they should, moreover, of necessity come from the entire ranges of different schools of criticism, genetic criticism, textual criticism, scholarly editing, genetic editing, and digital editing, both scholarly-at-large and genetic. Preliminarily to establishing a common platform of understanding, some basic 
terms would need to be reflected and their definitional differences in the several disciplines be laid open. Paul Eggert, for example, while aware of such differences (sometimes more, sometimes less) still operates with terms such as "document", "witness", "version", "intention", much on an Anglo-American system of coordinates. This serves his case, the set of his cases, well, and is not detrimental. Yet some conclusions drawn in the course of the book would be re-accentuated were other basic definitions and co-ordinations within the frameworks of the disciplines concerned admitted or considered. To admit to the full the notion that "text" is logically separable from "document", for example, would re-calibrate the systemic relationship between document and text; it might moreover, render "witness" obsolete. For the concept of the "version", so rightly essential to Eggert's case, it would be important to pursue the implications of the circumstance that Eggert from the Anglo-American angle can perceive it as largely intrinsic to a work's progression, while its definitional frame in German editorial scholarship is essentially extrinsic: what is a "version" is there due less to the work's progression than to the editor's decision to single out a given so-declared version on grounds of external circumstances of transmission and reception. Above all: the reviewer of The Work and the Reader in Literary Studies is - that is, I am, and remain to the end, deeply puzzled that Paul Eggert throughout staunchly sticks to the notion and over-all concept of "intention" very much still in its Anglo-American application. His deeply perceptive discussion of Joseph Conrad's mind- and health-racking struggle to achieve Under Western Eyes (1911; see also Conrad 2013) should have rendered inescapable the conclusion that the sense and significance of "intention" needs a thorough overhaul. None of Eggert's examples more than that of Conrad's Under Western Eyes cries out for a genetic approach. This, Eggert acknowledges. But to adhere, at the same time, to the notion of "intention" locks the genetic progression within a teleological framework that the progressive writing and especially the over-and-over re-reading, re-thinking and revising of that writing thoroughly countermands. Eggert establishes, in his monograph, that the future of scholarly editing, transactionally aimed comprehensively at literary studies, lies in the digital medium and through it in the digital edition. His discussion of Joseph Conrad's Under Western Eyes constitutes his best case that the digital edition requires the genetic dimension. The book does not resolve how it is to be attained. The genetic digital edition in full potential yet stands to be modelled. It is where Paul Eggert's notion of an "editing on the level of the work" should become realisable. This is a task yet ahead of us all.

To conclude, then: The Work and the Reader in Literary Studies is the most substantial book I am aware of today to lay out the land of literary study on foundations of documented transmission of works of literature: works and the texts that adumbrate them, written and re-written, read and re-read, and ever safeguarded by the manifold agencies of authors, scribes, typists and typesetters, digital key-strokers, publisher's editors, book historians, commercial or scholarly editors, and ever and ever again readers. In scope, the book unfolds 
on its choice of soundly reflected theoretical foundations an amazingly encompassing pragmatics of literary study in its specifics of textual criticism, editorial scholarship and richly variegated experience in mind-on and hands-on editing. It is a book indeed over which literary critics, textual critics and editors with long experience of their own, as well as early researchers, should ideally get together to pick up on its multitude of definitions, reflections and lines of argument. The historical moment is opportune: we are on the threshold or indeed in the very throes of the medial shift from the materially analogue to the binary digital curation both of our literary heritage and our culture's literary future. The disciplines we term today literary study, textual criticism, scholarly editing, digital humanities should feel called upon to de-compartmentalise themselves - also de-nationalise themselves - and unite in sustained debates to shoulder their united responsibility for reassessment and renewal. The Work and the Reader in Literary Studies forms an important point of entry to re-conceptualisings of literary study.

\section{Bibliography}

Conrad, Joseph, 2013. Under Western Eyes, edited by Roger Osborne and Paul Eggert. (The Cambridge Edition of the Works of Joseph Conrad. J.H. Stape and Alan Simmons, eds.). Cambridge: Cambridge University Press.

Harpur, Charles, 2019. The Charles Harpur Critical Archive, edited by Paul Eggert. Sydney: Sydney University Press. Available from: https://charles-harpur.org/Home/Site/ (Accessed: 2020-06-15). 